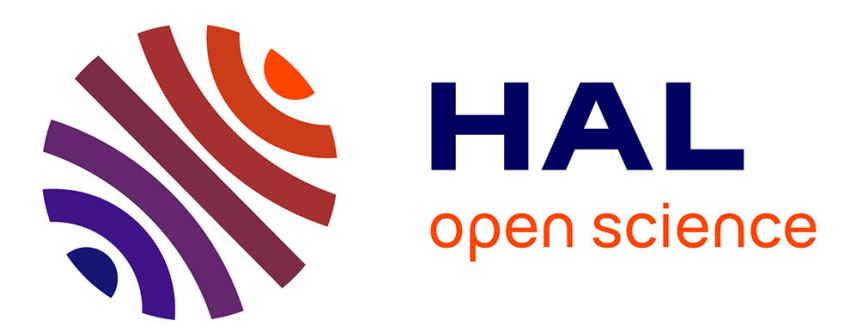

\title{
Adoption and Use of Tablet Devices by Older Adults: A Quantitative Study
}

Uchenna Ojiako, Jyoti Choudrie, Ukamaka Nwanekezie, Chike-Obuekwe Chikelue

\section{- To cite this version:}

Uchenna Ojiako, Jyoti Choudrie, Ukamaka Nwanekezie, Chike-Obuekwe Chikelue. Adoption and Use of Tablet Devices by Older Adults: A Quantitative Study. 18th Conference on e-Business, e-Services and e-Society (I3E), Sep 2019, Trondheim, Norway. pp.545-558, 10.1007/978-3-030-29374-1_44 . hal-02510113

\section{HAL Id: hal-02510113 \\ https://hal.inria.fr/hal-02510113}

Submitted on 17 Mar 2020

HAL is a multi-disciplinary open access archive for the deposit and dissemination of scientific research documents, whether they are published or not. The documents may come from teaching and research institutions in France or abroad, or from public or private research centers.
L'archive ouverte pluridisciplinaire HAL, est destinée au dépôt et à la diffusion de documents scientifiques de niveau recherche, publiés ou non, émanant des établissements d'enseignement et de recherche français ou étrangers, des laboratoires publics ou privés.

\section{(c)(1)}

Distributed under a Creative Commons Attribution| 4.0 International License 


\title{
Adoption and Use of Tablet Devices by Older Adults: A Quantitative Study
}

\author{
Uchenna Ojiako $^{1}$ Jyoti Choudrie $^{2}$ Ukamaka Nwanekezie $^{3}$ and Chike-Obuekwe \\ Chikelue $^{4}$ \\ University of Hertfordshire, Business School, Hatfield AL10 9EU, UK \\ 1 uchenna.ojiako18@gmail.com \\ 2 j.choudrie@herts.ac.uk \\ 3 makmek2004@yahoo.com \\ 4 chikejunior424@gmail.com
}

\begin{abstract}
Information and communication technologies have become essential for everyday activities. Recently, ubiquitous or mobile computing is the new trend whereby information and services can be accessed anywhere and anytime. However, not all groups of society are taking advantage of its benefits, of which the older population is one of such groups. This study aims to identify and evaluate the factors that influence the adoption, use and diffusion of tablet devices within the older population (aged 50 and above) in UK. From an online survey of 203 completed responses, Compatibility, Perceived Usefulness, Perceived ease of use, Trust, Attitude and Perceived behavioral control were identified as factors that affect the adoption and use of tablet devices. This study also provides the implications of the research to academia, industry and policy makers.
\end{abstract}

Keywords: Older Adults, Mobile Technology, Tablet Devices, Digital Divide, United Kingdom.

\section{Introduction}

Information and Communication Technologies (ICTs) currently plays a major role in the exponential growth and development of political, social and economic aspect of many nations [5]. It offers several benefits to individuals including online shopping, online banking and online social networks [6]. For demographic groups of society, particularly older adults who are the focus of this study, it offers benefits such as independence and connectedness, which can improve their quality of life [15]. However, there are still many who are not accepting and using ICT, which has let to a digital divide [30]. Digital divide is the term used to describe the inequality existing among people with physical access to digital technologies and those with limited or no access to digital technologies [18]. A demographic group affected by the digital divide is the older adult population [30].

Currently, countries around the globe are facing aging populations and concurrently, technology is evolving, thus, this situation highlights the importance of digitally including the older population. The United Kingdom (UK) is one of such countries 
facing an ageing population and also the digital divide. For instance, with respect to the digital divide, the Office for National Statistics (ONS) found that about 4.8 million adults in UK had never used the Internet as at the year 2017 [24]. In addition, in a report published by Age UK, nearly 3.8 million people aged $65+$ are non-users of the Internet while $59 \%$ of those aged $75+$ are also non-users [1]. In terms of the ageing population official statistics data revealed that in UK, the proportion of individuals aged 65 and over increased from 14.2\% to $18 \%$ between the years 1976 to 2016 [25]. While, the proportion of those aged 15 and under decreased from $24.5 \%$ to $18.9 \%$ between 1976 and 2016. Furthermore, in economic terms, the older population is of immense importance as government policies are removing barriers to employment that has led to organisations employing older adults [13]. Moreover, due to the medical advances and a better quality of life it has been predicted that this ageing society is likely to continue over the next decades, which further suggests that special attention should be paid to the older generation [25]. Also, the digital inclusion of older adults can be beneficial to UK's society especially with organisations currently using technological artifacts for conducting work-related activities, and the older population becoming the fastest growing proportion of the workforce [13].

Furthermore, ICTs are evolving leading to new innovations that now makes daily activities quicker, convenient and cheaper [6]. One of such innovations is ubiquitous or mobile computing, which has made information accessible anytime and anywhere. It is anticipated that this form of computing will be more effective in reducing the digital divide because of its capability of combining the integral benefits of wireless Internet and interactivity with its own unique characteristics namely, mobility, portability and flexibility $[11,28]$. One of the devices that have made this form of computing a reality is the tablet device. Tablet devices are also making a significant impact in encouraging the use of the Internet and ICT generally among the older population. For instance, tablet devices have plateaued over the years and changed the way older adults use the Internet [23]. Specifically, older adults aged 65-74 years using tablets to go online more than trebled in recent years in the UK, going from 5\% in 2012 to $17 \%$ in 2013 . However, this percentage remains low compared with younger age groups (e.g., $37 \%$ of adults aged $25-34$ years used tablets to go online in the last 3 months) [20]. The presence of ICTs has led to many daily activities becoming digital; thus, converting many societies into an Electronic society (e-society). However, for the e-society to be successful, it is essential that all citizens adopt and use technology, which as stated earlier is not occurring within the older adults population; thus a motivating reason for conducting this study. The adoption and use of ICTs especially mobile computing like the tablet devices is a growing research topic because it helps access the successful diffusion of technology in the society. However, there is limited study on the reasons older adults adopt and use tablet devices. Therefore, this study aims to identify and evaluate the factors that influence the adoption, use and diffusion of tablet devices within the older population (aged 50 and above) in UK. To achieve this aim, the following research questions were formed:

(a.) Is there an age difference in the adoption and use of tablet devices?

(b.) What are the factors enabling or hindering the adoption and usage of tablet devices especially among the older population 
To familiarise readers with the content of this paper, the following is provided. This section introduced the research problem, aims and research questions. This is followed by a background of the study, conceptual framework and hypotheses. The research approach, analysis and findings, discussions and limitations of this study are then provided. The conclusion and implications of this research draws the paper to a close.

\section{Background of Study}

\subsection{Mobile Technologies}

Ubiquitous or mobile technology enables faster and easier access to the Internet [11, 28]. For this study, the tablet device has been selected as an example of mobile technology considering that this particular device has become commonplace in modern society especially UK [2]. The tablet device is among one of the various mobile technologies that has made it possible to access information anytime and anywhere. It combines the features of a computer and a mobile phone to form a unique device [4]. These devices potentially offer numerous benefits some of which include continuous connectivity, as well as the provision of a means for multitasking [28]. Originally, the tablet device was intended as a supplement to desktop and laptop computers [21]. However, in recent times, this device has begun to replace the desktops and laptops. Research has shown that most individuals are currently moving from laptops and desktops towards smartphones and tablets. For instance, there was a decrease in the number of people accessing the Internet via laptop/desktop computer from $81 \%$ in 2014 to $71 \%$ in 2015 [21]. Meanwhile, between the same period, the percentage of people accessing the Internet via smartphones and tablet devices increased by $4 \%$ and $6 \%$ respectively. Additionally, the rate of the adoption and usage of the tablet device especially among older adults has increased over time. For instance, the number of 65-74 years old going online with a tablet device in the UK, increased by $9 \%$ between the years 2013 to 2015 [21]. Thus, to summarise, the popularity of the tablet has led to it being used in various areas of society including the educational, social and medical sectors.

\subsection{The Digital Divide}

As ICTs including mobile technology are expanding, and the ageing of population continues to progress, there is an increasing need for studies relating to the adoption of technologies among older adults. Over the last decades, there has there has been an increment in life expectancy in the UK and it is further projected that by 2036, over half of the local areas in UK will experience a $25 \%$ increase in the population of citizens aged 65 and over [22]. The digital divide is one of the negative consequences of the presence of ICT in society and has led to numerous debates among academia and policy makers. Consequently, the older population is one of the marginal groups negatively affected by the digital divide $[5,30]$. Some of the reasons attributed to the lack of engagement among the older population include the difficulties encountered in embracing the changes that these technologies have brought to society especially considering most of these adults were not raised with technology [6]. Furthermore, Choudrie et al. [5] reckons that some health issues such as vision impairment, memory loss and arthritis prevent older adults from using technology, which has led 
to their exclusion from the e-society. Therefore, these identified issues have affected ICT adoption pattern in this group. Furthermore, most of the times, older adults prefer to sustain their independence for as long as is possible $[5,30]$. However, age-related deficiencies among other factors can challenge the achievement of this independence desired by older adults. Devices such as tablet computers might be a solution for some of these challenges because these devices provide convenient and prompt access to several benefits [4]. These benefits include sustaining connections with family and friends as well as using the current healthcare systems. This will in turn reduce loneliness and isolation normally experienced by older adults [30]. Moreover, considering that the functioning of modern society now depends heavily on technology, it is important that every member of the society adopt technology, which highlights the importance of bridging the digital divide. Additionally, with the ageing of nations, older adults are of immense importance to the economy and society at large. Therefore, these older adults need to feel included, valuable and part of society. This further emphasises the importance of ensuring that the older population engage in the current technology adoption and usage trend. This will in turn ensure healthy and successful ageing in these adults as well as secure the future of the economy [6].

Having discussed the background of the study, the following discusses the development of the conceptual framework and hypotheses formulation.

\section{The Conceptual Framework and Hypotheses Formation}

In information system (IS) research, there is an emerging need to understand why people behave in certain ways when it comes to adopting and using technology. To ensure the selection of suitable constructs, studies on mobile technologies were reviewed to identify the theories that have been employed in addressing this subject area. Generally, since the inception of mobile technology, studies have been carried out to address the adoption of mobile technologies in various sectors. For instance, in 2011, an empirical study investigating the use of mobile technology to conduct mobile commerce and financial services also emerged [12]. This study combined attributes from Roger's diffusion of innovation theory with attributes from knowledgebased trust to assess mobile banking adoption [12]. Result from this study showed that perceived relative advantage, ease of use, compatibility, competence and integrity have significant impact on attitude towards adopting mobile banking. Result also indicated that attitude has a significant influence on behavioural intention to adopt mobile banking [12]. Furthermore, with respect to tablet devices, Moran et al. [16] in their study employed a modified UTAUT model to examine the implementation of tablet device in a higher education institution. Findings from this study showed that performance expectancy, self-efficacy, effort expectancy and attitude were significant predictors of behaviour intention. However, social influence and anxiety were not significant in predicting behaviour intention [16]. Moreover, some studies assessing the adoption of tablet device from the consumer's perspective have also been carried out. For example, Hur et al. [10] conducted a study in South Korea to explore the factors that influence a consumer's intention to use a tablet device. This study applied a modified TAM model and analysed the data gathered using partial least squares (PLS) analysis. Result indicated that perceived usefulness and enjoyment have a posi- 
tive impact on attitude while; social influence and attitude have a positive impact on intention to use tablets [10]. Following the review of previous theories, this study built upon the decomposed theory of planned behaviour (DTPB) and trust theory in developing the conceptual framework. Subsequently, each of the constructs selected for the study along with the relevant hypothesis associated with it is discussed in details below:

Compatibility (COMP): This is the extent to which an innovation conforms to an individual's existing values, past experiences and needs [29]. This means that potential adopters of technology often require the new technology to be compatible with their existing lifestyle or cultural norm otherwise; this will result in a slower or none adoption rate [12]. Moreover, a few studies have highlighted the significance of compatibility in determining attitude and intention to adopt technology [12, 31]. However, consistent with the rationale and application in DTPB, the compatibility construct is linked to the attitude variable. In addition, to address this compatibility construct, the following hypothesis (H1) was created.

H1: Compatibility has a significant effect on an individual's attitude towards adopting and using a tablet device.

Perceived usefulness (PU): This construct refers to the extent to which using technology will increase productivity and aid in the achievement of a desired goal [10]. For this research, perceived usefulness is used as an antecedent of attitude. To test the perceived usefulness construct, the following hypothesis (H2) was generated.

H2: Perceived usefulness will significantly influence an individual's attitude towards adopting and using a tablet device.

Perceived ease of use (PEOU): The usability of ICT is an important factor considered by users especially older adults during the process of adoption decision-making [5]. For clarification purposes, usability is defined as the ease with which a technological artefact is learnable and usable [19]. In the light of this, the perceived ease of use of the tablet device is an important aspect to examine in this study. Thus, for this study, perceived ease of use is posited as a determinant of attitude. To address this construct, the following hypothesis (H3) was developed.

H3: Perceived ease of use will significantly influence an individual's attitude towards adopting and using a tablet device.

Trust (TRU): Trust was also identified as a relevant construct for this study because it is a fundamental factor when apprehension, risk and uncertainty are concerned. In this case, it is related to the belief that technology in the form of tablet devices will be safe to use as well as the belief that it will do what it is expected to do. Furthermore, previous studies have found that trust is a key factor for assessing technology adoption and use pattern especially among the older population [27, 34] Considering this, the trust construct is used as an antecedent of attitude towards using and the intention to use a tablet device. To measure this construct, it was divided into trusting beliefs, institutional based trust and disposition to trust [27]. The following hypotheses ( $\mathrm{H} 4$ and $\mathrm{H} 5$ ) were generated.

H4: An individual's perception of trust significantly affects his/her attitude towards adopting and using a tablet device.

H5: An individual's perception of trust significantly affects his/her intention to adopt and use a tablet device.

Attitude (ATT): Attitude is defined as an individual's response towards a concept or performing certain behaviour. It is a person's salient belief regarding the consequenc- 
es of carrying out an action [32]. In addition, in terms of age and technology adoption, attitude has been identified as a key determinant of behaviour [17]. Thus, this study identified attitude as a relevant construct and it is used as a determinant for intention behaviour. In addition, to assess this construct, the following hypothesis (H6) was created.

H6: An individual's attitude towards using a tablet device directly influences his/her intention to adopt and use the device.

Subjective norm (SN): Subjective norm was also identified as a suitable construct for this research. This construct postulates that a person's behaviour is based on the influence of important people in their life [32]. This means that if a person perceives that people important to them think they should act in a particular way, then, they are motivated to comply. This study posits $\mathrm{SN}$ as a determinant of intention to use. In line with this, the following hypothesis (H7) was developed.

H7: Subjective norm has a significant effect on an individual's intention to adopt and use a tablet device.

Perceived behavioural control (PBC): This construct refers to the level of one's perception with regards to the access to resources and opportunities required for performing a specific behaviour. The rationale behind this construct is that a person's behaviour is often dependent on how much resources as well as confidence the person has at their disposal to perform the required action [32]. In this study, this construct is used as a determinant of the intention to use. Considering this, the hypothesis (H8) was thus generated to address this construct.

H8: Perceived behavioural control has a direct effect on an individual's intention to adopt and use a tablet device.

Intention to use tablet device (INT): The intention to perform any action is often dependent on attitude, subjective norm and perceived behavioural control [10, 32]. However, to account for the issue of apprehension often linked with adopting technology, this study included trust along with ATT, SN and PBC in the examination of intention behaviour. Furthermore, an individual's need to carrying out their intentions given the opportunity usually results in the actual behaviour [32]. Therefore, for this study, intention behaviour is the direct antecedent of actual behaviour. Considering the above discussion on intention and actual use, the following hypothesis (H9) was created.

H9: An individual's intention behaviour towards a tablet determines their actual use of the tablet.

Having provided details on the selected constructs and relating hypotheses, the conceptual framework for this study is presented in figure 1. 


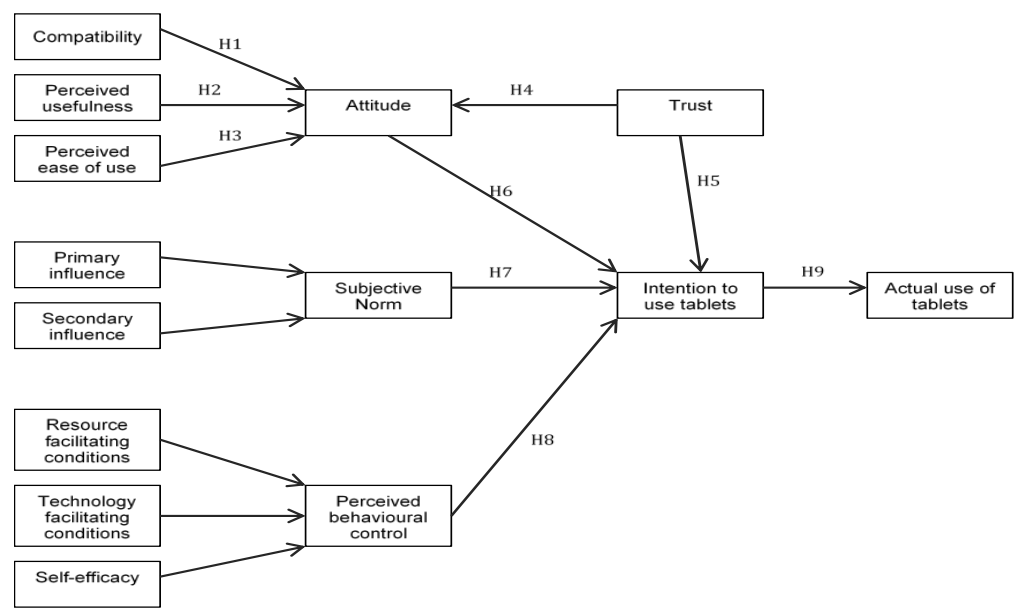

Fig. 1. The framework for tablet device adoption (FTDA).

\section{$4 \quad$ Research Approach}

A quantitative approach was employed to collect data for this research using survey questionnaires. The questionnaire contained mainly close-ended questions and was divided into five sections. In addition, a reflective measurement model was employed and the measurement items for each construct were adopted from previous studies with some modification to suit the research context. This study also used a 7-point Likert scale $(1=$ strongly disagree to $7=$ strongly agree) to measure the constructs. To acquire data, the sample site selected for this study was the Hertfordshire County of UK, which is the second most populated area in the east of England with a population of approximately 1.2 million people as at 2015 [9]. Moreover, statistics obtained from the Office for National Statistics (ONS) showed that the proportion of those aged 50 years and over living in the County is about 35\% [26]. Thus, it was based on these details as well as its proximity to the researcher that Hertfordshire County was selected as a suitable site for the study.

Furthermore, to measure how suitable the questionnaire is in achieving the intended purpose, the questionnaire was pre-tested using a panel consisting of 20 experts. These experts consisted of academics (7), industrial specialist (4) and the prospective target population (9). This was then followed by a pilot study, which was carried out using a combination of non-random sampling method including snowball and purposive sampling technique. Moreover, the survey questionnaire was distributed both in paper and online form in order to boost the response rate and reach the target population. Data was collected between the periods of 4th of May 2016 to 15th of July 2016. Initially, the snowball method involved the recruitment of already established contacts via emails and word-of-mouth. These selected contacts were then used to recruit more participants from their own established contacts and this led to the snowball sampling technique employed. Following this, 455 questionnaires were distributed purposively in some household in Hertfordshire. This resulted in 203 completed responses consisting of 168 softcopies and 35 hardcopies. Furthermore, according to Dillman et al. [7], 
for a pilot study to make an impact, it is the recommended number of responses should be between 100 and 200 responses. Thus, based on this, the number of responses (203) collected for this pilot study is considered suitable.

\section{$5 \quad$ Analysis and Findings \\ 5.1 Descriptive Statistics}

To verify if there was a difference in tablet usage, younger adults (18 - 49 years old) and the older adults (50 years and over) were targeted. In surveys, bias can arise due to the sampling strategy and or non-response. To minimise this bias, this study applied a weight adjustment technique, which was done by using the data analysis tool SPSS version 23. From the result, the participants for this study consisted of 114 $(56.2 \%)$ females and $89(43.8 \%)$ males. In terms of age, participants were split into seven age groups including 18-29 years old, 30-39 years old, 40-49 years old, 50-59 years old, 60-69 years old, 70-79 years old and 80+ years old. Result based on these age groups showed that $38(18.7 \%)$ of the respondents were 18-29 years old, 30 (14.8\%) were $30-39$ years old, $17(8.4 \%)$ were $40-49$ years old, $26(12.8 \%)$ were 50 59 years old, $58(28.6 \%)$ were $60-69$ years old and $70-79$ and $80+$ age groups were 34 $(16.7 \%)$ and $0(0 \%)$ respectively. Moreover, results showed that out of the 203 respondents, $56.7 \%$ used a tablet device, $26.6 \%$ did not use a tablet device and had no intention of using one while $16.7 \%$ did not currently use a tablet device but had the intention to purchase one. Furthermore, for users of tablets, 55.7\% belonged to the older group (50 years and over) while $44.3 \%$ belonged to the younger group (18 - 49 years). This result indicated and confirmed the suggestion of BBC [2] that the use of the tablet device has significantly influenced the number of citizens going online especially among the older adults. Furthermore, results also showed that compared to other age groups, the highest adopters of tablet devices belonged to the 60-69 years age group $(31.4 \%)$ while the highest non-adopters were from the $70-79$ years age group with $37 \%$.

Additionally, in terms of education, it was found that the highest percentage of tablet device adopters belonged to those who had a Bachelor's degree with $31.3 \%$. In terms of gender, women adopted tablet devices more than men with $57.4 \%$ of adopters representing women while $42.6 \%$ representing men. This suggests that there could be a connection between gender and tablet device adoption. In terms of health, it was observed that the better the health status, the more likely the adoption of a tablet device. This suggestion was based on the finding that $56.5 \%$ of adopters indicating that their health status was excellent while $35.7 \%, 6.1 \%$ and $1.7 \%$ of adopters indicated that their health status was good, fair and poor respectively.

\subsection{Path Analysis}

To ensure reliability and validity of constructs, Cronbach's alpha, rho_A, composite reliability and average variance extracted (AVE) were employed. As a rule of thumb, the acceptable value for Cronbach's alpha, rho_A, composite reliability should be greater than or equal to 0.7 respectively while the acceptable value for AVE should be greater than or equal to 0.5 [8]. Based on this recommendation, the values found for each of the measurement test exceeded $0.7,0.7,0.7$ and 0.5 respectively. 
Using SmartPLS 3.0, path analysis for all age group was conducted in order to determine the path coefficient $(\beta)$. Furthermore, bootstrapping was applied to the PLS analysis using 0.05 level of significance and this generated $t$-values and corresponding $p$-values. From the result, it was observed that $\mathrm{PBC}$ had the strongest influence on INT with $\beta=0.382, t=2.954$ and $p=0.003$. This was followed by ATT with $\beta=0.314$, $t=2.461$ and $p=0.014$. However, $\mathrm{SN}$ was considered insignificant in predicting the intention to use tablets with $\beta=-0.043, t=0.464$ and $p=0.643$. TRU also was considered insignificant in determining the intention to use with $\beta=0.108, t=1.206$ and $p=0.228$. Result indicated that PEOU had the strongest impact on ATT with $\beta=0.293, t=4.128$ and $p=0.000$. Additionally, COMP, PU and TRU proved to be significant in determining the ATT with values $(\beta=0.258, t=2.913$ and $p=0.004),(\beta=0.286, t=3.375$ and $p=0.001)$ and $(\beta=0.183, t=3.362$ and $p=0.001)$ respectively.

\subsection{Multi-Group Analysis}

Multi-group analysis (MGA) was also performed in order to compare the age group categories (younger and older group). Among the older and younger group, PBC had the strongest influence on the INT to use tablet with $(\beta=0.360, t=2.265$ and $p=0.024)$ and $(\beta=0.455, t=2.091$ and $p=0.037)$ respectively. Additionally, both groups showed that SN and TRU were insignificant in determining INT. Furthermore, it is noteworthy that among the older group, $\operatorname{PEOU}(\beta=0.384, t=5.186$ and $p=0.000), \operatorname{PU}(\beta=0.375$, $t=4.214$ and $p=0.000)$ and TRU $(\beta=0.127, t=2.651$ and $p=0.008)$ were significant in determining ATT while COMP $(\beta=0.147, t=1.600$ and $p=0.110)$ was insignificant in relation to ATT.

For the younger group, result indicated that TRU $(\beta=0.255, t=2.063$ and $p=0.040)$ and COMP $(\beta=0.378, t=2.080$ and $p=0.038)$ were significant in determining ATT. Meanwhile, PEOU $(\beta=0.143, t=1.107$ and $p=0.269)$ and $\mathrm{PU}(\beta=0.223, t=1.722$ and $p=0.086$ ) were insignificant in determining ATT.

Additionally, ATT was significant in determining INT among the older group $(\beta=0.302, t=1.983$ and $p=0.048)$ while it was insignificant among the younger group $(\beta=0.374, t=1.646$ and $p=0.100)$.

\subsection{Coefficient of Determination}

Coefficient of determination $\left(\mathrm{R}^{2}\right)$ is used to determine the extent an independent variable can explain a dependent variable. The closer the value is to 1 , the better the fit, thus, $\mathrm{R}^{2}$ values that range from 0.5 and above are often recommended [8, 33]. Based on this, $\mathrm{R}^{2}$ derived for the key dependent variable (intention to use tablets) is 0.527 . This implies that the FTDA framework can explain about $52.7 \%$ of the variability in respondents' intention to use tablets. This value indicates the sufficiency of FTDA in predicting behaviour intention with regards to tablet devices. Additionally, the $\mathrm{R}^{2}$ value for the attitude variable is 0.868 , which means that about $86.8 \%$ of the respondents' attitude formation can be explained by their perception of the tablet device in terms of compatibility, trust, perceived ease of use and perceived usefulness.

\section{Discussions and Limitations of Study}

The following limitations should be noted when interpreting and making generalisations about the results. 


\subsection{Limitations of Study}

The limitations of this study are specified to provide clarity on the level of generalisation that can be drawn from the results. Firstly, in ensuring the feasibility of completing the study within the required timeframe, data was collected from Hertfordshire County, UK, which reduces the applicability of the result to one part of UK. Therefore, future research should consider assessing the adoption of tablet devices in other parts of the Country. In addition, data collection for the quantitative study utilised a purposive and snowball sampling technique. Although, bootstrapping and weight adjustments were applied to the data in order to make up for the sampling variances. However, these sampling techniques are non-probability method, which reduces the extent of generalisation that can be drawn from the results of this study. Therefore, it is recommended that an alternative method be used for future studies. Overall, considering these limitations, it is suggested that caution should be taken when interpreting the results of this study.

\subsection{Age Difference in the Adoption and Use of Tablet Devices}

A study by Broady et al. [3] suggested that although older adults may not use technology as much as the younger adults however, the negative stereotypes of older adults being technophobic and incapable of using ICT is now outdated. Evidence of this was found in this study that given the right device, this stereotyping of older adults has faded. Specifically, a comparison between the younger adults (18-49 years old) and the older adults (50+ years) was conducted and the derived result indicated that the older group $(55.7 \%)$ adopted the tablet device more than their younger counterpart (44.3\%). This finding almost agrees with Magsamen-Conrad et al. [14] who found that there was a significant generational difference in the use of tablets. Furthermore, older adults' use of the tablet device more than their younger counterpart might be because the design of the tablet device has some ageing specific features, which makes it a suitable device for the older adults. For instance, most tablet devices have large screen size, which will be suited for older adults who are visually impaired. In addition, its mobility feature will be suited for older adults who have mobile issues or back problem or basically require being comfortable while using any device. Consequently, this result further confirms that there is an age-related digital divide $[5,30]$ however, with regards to tablets, the older adults are on the positive side of the divide. This further provides evidence that a tablet device offers a better chance of ensuring that older adults are digitally included. Subsequently, in the category of those planning to adopt tablets, $44.1 \%$ of this category belongs to the $50+$ years age group. This indicates a willingness on the part of older adults to use ICT, which coincides with the finding of Broady et al. [3] that older adults are not technophobic especially with respect to the tablet device. Furthermore, the general result including all age group revealed that PBC and ATT were significant in determining INT. This finding is consistent with previous ICT adoption and use studies [17, 32] that revealed that factors such as ATT and PBC often affects an individual's intention to adopt. Subsequently, the theories were further tested to assess whether there was a difference between the young and old in terms of the hypothesised constructs. To achieve this, a multi-group analysis (MGA) was employed to compare both groups. It 
was observed that both groups shared some similarities in factors that determine ATT and subsequently, INT. For example, within the two groups, PBC was significant in determining INT and TRU was significant in determining ATT. This finding is similar to a study by Broady et al. [3] where it was suggested that similar factors influence younger and older adults. Furthermore, in this study, it was also observed that the two groups shared some differences with regards to the hypothesised constructs. For instance, ATT was found significant in determining INT among the older group but was not significant among the younger adults. Moreover, among the older group, PU and PEOU were significant in determining ATT. This finding almost agrees with the work of Hur et al. [10] where it was found that PU and perceived enjoyment significantly impacted on ATT. In addition, COMP was found significant in determining ATT among the young group but was not significant among the older group.

\section{Conclusions}

This study aimed to identify and evaluate the factors that influence the adoption, use and diffusion of tablet devices within the older population (aged 50 and above) in UK. To achieve this aim, a conceptual framework (FTDA) was developed and tested using data collected quantitatively. From the results of this study, the following conclusions and recommendations were obtained. Firstly, the findings of the study sufficiently demonstrated that the FTDA model proposed was appropriate in predicting intention behaviour and attitude towards adopting and using tablet devices. This was deduced from the $\mathrm{R}^{2}$ values of $52.7 \%$ and $86.8 \%$ respectively. Furthermore, the digital divide research has shown some considerable variation in the way older adults adopt and use technology in comparison to their younger counterpart. For instance, Selwyn [30] highlighted that older adults are usually on the negative side of the digital divide and this issue has resulted in debates among academia and policy makers. Furthermore, this significant variation with regards to older adults adoption of ICT is currently a social problem and might sooner or later affect the economy at large. This is because there is an increase in the number of older people in the labour market as a result of the ageing of populations [25] and simultaneously, technology continues to penetrate everyday activities including organisations. Thus, older adults adoption and use of technology is of importance in the growth and development of a stable economy. In the light of this, the result of this study showed that in terms of tablet devices, older adults are on the positive side of the digital divide. Thus, it can be concluded that the use of tablet devices is a potential solution for reducing the digital divide when it comes to older adults participation in the information society.

\subsection{Implications of Research}

The findings from this study have numerous implications for academia, industry and policy-makers. Therefore, the following provide details on the implications of the study with respect to the three categories mentioned.

For academia, past research have focused on the presence of the digital divide and its effect on modern society. Some of these studies have examined the age-related digital divide especially from the perspective of older adults. Therefore, this study contributes to the theoretical and empirical research on the digital divide as well as studies on older adults adoption and use of technology. Moreover, this study offers an 
insight on the factors that influence the adoption and use of tablet devices especially from the perspective of older adults residing in UK.

For policymakers, considering that policymakers often look for cost-effective schemes that will help provide support to older adults without compromising their safety. Meanwhile, for example, this study found that tablet device has the potential of helping older adults remain independent and socially included, which in turn might lead to an improvement in their quality of life. Thus, these finding from this study offer information that policymakers might manipulate to facilitate citizens adoption and use of ICT, which in turn could influence its successful diffusion in the UK.

Furthermore, for industry, the result of this study also has some implications for the developers of technology especially with respect to designing suitable technology for older adults. For instance, it was noted that age-related changes in health impacts on the adoption of technology. Thus, developers of technology should pay attention to the usability features of the technology in order to encourage the older adults' market segment.

\section{References}

1. Age UK, https://www.ageuk.org.uk/globalassets/age-uk/documents/reports-andpublications/later_life_uk_factsheet.pdf?dtrk=true, last accessed 2018/02/13.

2. BBC News, http://www.bbc.co.uk/news/technology-27205172, last accessed 2017/04/25.

3. Broady, T., Chan, A., Caputi, P.: Comparison of older and younger adults' attitudes towards and abilities with computers: Implications for training and learning. British Journal of Educational Technology, 41(3), 473-485 (2010).

4. Burford, S., Park, S.: The impact of mobile tablet devices on human information behaviour. Journal of Documentation, 70(4), 622-639 (2014).

5. Choudrie, J., Ghinea, G., Songonuga, V.N.: Silver surfers, e-government and the digital divide: An exploratory study of UK local authority websites and older citizens. Interacting with Computers, 25(6), 417-442 (2013).

6. Damant, J., Knapp, M., Freddolino, P., Lombard, D.: Effects of digital engagement on the quality of life of older people. Health and Social Care in the Community, 25(6), 1679-1703 (2017).

7. Dillman, D.A., Smyth, J.D., Christian, L.M.: Internet, phone, mail, and mixed-mode surveys: the tailored design method. $4^{\text {th }}$ edn. John Wiley \& Sons, New Jersey (2014).

8. Hair, J.F., Black, W.C., Babin, B.J., Anderson, R.E., Tatham, R.L.: Multivariate data analysis. $7^{\text {th }}$ edn. Pearson Education Limited, Harlow (2014).

9. Herts

Insights, http://atlas.hertslis.org/profiles/profile?profileId=79\&geoTypeId=16\&geoIds=E10000015\#iasPr ofileSection4, last accessed 2017/04/25.

10. Hur, W.M., Kim, H., Kim, W.M.: The Moderating Roles of Gender and Age in Tablet Computer Adoption. Cyberpsychology, Behavior, and Social Networking, 17(1), 33-39 (2014).

11. Leung, L.: Using tablet in solitude for stress reduction: An examination of desire for aloneness, leisure boredom, tablet activities, and location of use. Computers in Human Behavior, 48, 382391 (2015).

12. Lin, H.F.: An empirical investigation of mobile banking adoption: The effect of innovation attributes and knowledge-based trust. International Journal of Information Management, 31(3), 252-260 (2011).

13. Lusardi, A., Mitchell, O.S.: Baby boomer retirement security: The roles of planning, financial literacy, and housing wealth. Journal of Monetary Economics, 54(1), 205-224 (2007). 
14. Magsamen-Conrad, K., Upadhyaya, S., Joa, C.Y., Dowd, J.: Bridging the divide: Using UTAUT to predict multigenerational tablet adoption practices. Computers in Human Behavior, 50, 186196 (2015).

15. Mitzner, T.L., Boron, J.B., Fausset, C.B., Adams, A.E., Charness, N., Czaja, S.J., Dijkstra, K., Fisk, A.D., Rogers, W.A., Sharit, J.: Older adults talk technology: Technology usage and attitudes. Computers in Human Behavior, 26(6), 1710-1721 (2010).

16. Moran, M., Hawkes, M., Gayar, O.E.: Tablet personal computer integration in higher education: Applying the unified theory of acceptance and use technology model to understand supporting factors. Journal of Educational Computing Research, 42(1), 79-101 (2010).

17. Neves, B.B., Amaro, F., Fonseca, J.R.: Coming of (old) age in the digital age: ICT usage and non-usage among older adults. Sociological Research Online, 18(2), 1-14 (2013).

18. Niehaves, B., Plattfaut, R.: Internet adoption by the elderly: employing IS technology acceptance theories for understanding the age-related digital divide. European Journal of Information Systems, 23 (6), 708-726 (2014).

19. Nielsen, J.: Usability 101: Introduction to usability. (2003).

20. Ofcom, https://www.ofcom.org.uk/_data/assets/pdf_file/0020/58223/2014_adults_report.pdf, last accessed 2017/01/30

21. Ofcom, https://www.ofcom.org.uk/_data/assets/pdf_file/0024/26826/cmr_uk_2016.pdf, last accessed 2017/01/30.

22. Ofcom, https://www.ofcom.org.uk/about-ofcom/latest/media/media-releases/2017/rise-socialseniors, last accessed 2018/03/04.

23. Ofcom, https://www.ofcom.org.uk/research-and-data/multi-sector-research/cmr/cmr2018/summary, last accessed 2019/02/26.

24. ONS,

https:/www.ons.gov.uk/businessindustryandtrade/itandinternetindustry/bulletins/internetusers/2 017 , last accessed 2018/02/12.

25. ONS,

https://www.ons.gov.uk/businessindustryandtrade/itandinternetindustry/bulletins/internetusers/2 017, last accessed 2018/02/12.

26. ONS, https://www.nomisweb.co.uk/query/asv2htm.aspx, last accessed 2017/04/25.

27. Pappas, I., Mikalef, P., Giannakos, M., Pavlou, P.: Value co-creation and trust in social commerce: An fsQCA approach. In Proceedings of the 25th European Conference on Information Systems (ECIS), pp. 2153-2168, Guimarães, Portugal (2017).

28. Park, S.: Always on and always with mobile tablet devices: A qualitative study on how young adults negotiate with continuous connected presence. Bulletin of Science, Technology \& Society, 33(5-6), 182-190 (2013).

29. Rogers, E.M.: Diffusion of innovations. $4^{\text {th }}$ edn. The Free Press, New York (1995).

30. Selwyn, N.: Apart from technology: understanding people's non-use of information and communication technologies in everyday life. Technology in Society, 25(1), 99-116 (2003).

31. Shaikh, A.A., Karjaluoto, H.: Mobile banking adoption: A literature review. Telematics and Informatics, 32(1), 129-142 (2015).

32. Taylor, S., Todd, P.A.: Understanding information technology usage: A test of competing models. Information Systems Research, 6(2), 144-176 (1995).

33. Vinzi, V.E., Trinchera, L., Amato, S.: Handbook of partial least squares: Concepts, methods and applications. In: Vinzi, V.E., Chin, W.W., Henseler, J., Wang, H. (eds.) (2010).

34. Vroman, K.G., Arthanat, S., Lysack, C.: "Who over 65 is online?" Older adults' dispositions toward information communication technology. Computers in Human Behavior, 43, 156-166 (2015). 